\title{
Cultivation of Students' Safety Consciousness in Analytical Chemistry Experiment
}

\section{Wenyan Nie}

Zibo Vocational Institute, Zibo, Shandong, China

\begin{abstract}
Analytical chemistry experiment is one of the basic courses of chemistry major. It mainly cultivates students' basic operation skills of analytical chemistry and lays a good foundation for the follow-up courses and actual work. However, there are security risks in the process of chemistry experiments. This article expounds the importance of the cultivating students' safety consciousness, discusses the potential hazards in analytical chemistry experiments, and puts forward corresponding schemes for cultivating students' safety awareness and proves their effectiveness.
\end{abstract}

Key words: analytical chemistry experiment; laboratory safety; safety conscious

\section{Introduction}

Recently, university laboratory safety accidents occur frequently, leading to different degrees of casualties, property losses, panic among students and parents, even fear of experiment, creating an abominable social influence. Experiment is a compulsory course required for students majoring in chemistry, biology, physics, materials, etc. Students can experience intuitively through manual operations and experiments, which helps them understand the abstract textbook knowledge and profits, thereby fostering innovative consciousness and improving the ability to solve practical problems. Especially for students majoring in chemistry, it is important to master chemical experiment skills, which will be of great benefit to their further studies or practical work. A lot of chemicals will be inevitably used in chemical experiment, and some of them are inherently dangerous. In addition, there may be other dangers such as poisoning, burning, explosion, electric shock, etc. during the experiment. According to the investigation, safety accidents are mainly caused by subjective factors, such as lack of safety consciousness, although objective factors also have a certain influence. So how to cultivate students' safety consciousness during analytical chemistry experiment teaching process?

\section{Existing Potential Safety Hazards}

Analytical chemistry experiments require students to master typical analytical methods and basic operations of quantitative analysis. During these experiments there are many potential safety hazards.

\subsection{Objective factors}

The reagents and instruments used in the experiment are inherently dangerous, such as strong acid, strong alkali, open flame, gas, etc. In some experiments there are only one or two dangerous factors. For example, concentrated hydrochloric acid used in the "Determination of Industrial Alkali" experiment is volatile in the air, and highly corrosive to the respiratory tract and clothing. But some experiments have more dangerous factors. For example, in the experiment, "Determination of the Content of barium in $\mathrm{BaCl}_{2}-2 \mathrm{H}_{2} \mathrm{O}$ ", a lamp temperature furnace is used, which brings danger by 
open flames and high temperature (temperature reaches $850^{\circ} \mathrm{C}$ ), and there is also risk of burns and scalds. In addition, sulfuric acid, Nitric acid, hydrochloric acid and other highly corrosive inorganic acids are also used in this experiment.

In addition to these dangerous chemical reagents and instruments, glass products, such as beakers, pipettes, conical flasks, glass rods used in most chemistry experiments are also easy to break and scratch students. Once the wound comes into contact with chemical agents, it will cause serious consequences.

\subsection{Subjective factors}

Unsafe behaviors of students are subjective factors, specifically including:

a. Some students don't pay enough attention to laboratory safety and have a fluke mentality.

b. The students rarely touch chemical reagents and instruments, and lack of safety knowledge, so they know nothing about the consequences of non-standard operation.

c. Without adequate rest, students' mental fatigue during class will cause operational errors, or slow response when encountering unexpected situations, which lead to serious consequences.

Analysis found that $88 \%$ of safety accidents are caused by people. So it is necessary to enhance students' safety awareness.

\section{Solutions}

Through the above analysis, we have formulated corresponding solutions to the potential safety hazards in analytical chemistry experiment. For example, setting up full-time laboratory staff who are responsible for dealing with dangerous chemical reagents, preparing the reagents required for the experiment and storing them in right reagent bottle, putting on eye-catching labels indicating the solution name, concentration, preparation time and expiration date, etc. The dangerous reagents are kept in different categories, which greatly reduces the possibility of students directly contacting the reagents. And we have taken the following effective measures to cultivate students' safety awareness.

\subsection{Self-study and examination of safety knowledge before class}

Before class, laboratory safety laws and regulations, laboratory rules, and safety knowledge are pushed to students through the network platform. Advanced "Internet + " technology enables students to learn safety knowledge anytime and anywhere, which is conducive to improving learning efficiency. We require freshmen to pass the laboratory safety education test before they are eligible to enter the laboratory. Through comprehensive and systematic safety education, students can master more laboratory safety knowledge before taking experimental classes, improve safety awareness, strengthen prevention and emergency rescue capabilities, and provide a strong guarantee for the development of experimental classes in the future.

\subsection{Teaching and supervision of safety knowledge in class}

we also devote 4 class hours to give students a detailed explanation of laboratory safety knowledge, such as how formaldehyde, ammonia and other irritating odors cause gas hazard, and what are the consequences of improper use of gas lamps. Before each experimental project start, teacher should elaborate not only the background knowledge, experimental purpose, principle, procedure, but also the safety accidents that may occur during the experiment, demonstrate in class, and tell students what serious consequences might be caused if such an accident occurs, making students feel awe in chemistry experiment, arousing their attention and enhancing their safety awareness. For example, in the experiment, "Determination of Barium Content in $\mathrm{BaCl}_{2} \cdot 2 \mathrm{H}_{2} \mathrm{O}$ ", there will be steps of drying the filter paper, carbonization and ashing, etc. When drying, it is necessary to emphasize using a small reflective flames to heat the middle of the crucible lid, and do not heat directly or use large fires, otherwise the filter paper will burn and be dangerous. And when drying for carbonization and ashing, it must be ensured that the filter paper is dry, otherwise a lot of black smoke will be produced which can cause 
discomfort. The details of these experimental operations are summarized by the teacher in the several years of teaching work. Only by telling the students of these dangerous points in advance can they attract attention, and once a problem occurs, the students will not be too frightened to make things worse.

\subsection{Standardizing experimental operation}

Good experimental operation habit is an important prerequisite for the safety of chemical experiments. So we formulate a series of operating specifications, and require students to strictly comply with. The details are as follows.

First, direct contact with chemicals and dangerous substances without face mask and gloves is strictly prohibited. Second, when pipetting solution, the ear wash bulb must be used along with pipette, and the tip of pipette should be below the liquid level. Clean the pipette immediately if pipette corrosive liquids such as sodium hydroxide or toxic solutions such as potassium dichromate. Third, when opening the volatile reagents (ammonia water, hydrochloric acid), etc., the mouth of the bottle must not face people, and it should be operated in a fume hood. Fourth, the reagents and consumables used must be placed clearly, well marked. Mixed use is forbidden. Fifth, after the experiment, all the consumables used must be cleaned and returned to their place and the reagents placed neatly. Students can only leave after the teacher checks and signs them. In addition, we will also carry out laboratory safety knowledge lectures, competitions, etc. to strengthen students' safety consciousness.

\section{Conclusions}

We divide the risk factors in the analytical chemistry experiment class into subjective and objective factors. Then we propose corresponding solutions to cultivate students' safety consciousness, that is, pre-class safety knowledge learning and examination, class safety knowledge teaching and management supervision, and experimental operation safety regulations. Through the joint efforts of teachers and students, under the premise of ensuring the safety of the experiment, the students have learned knowledge, mastered the experimental operation skills, and achieved good teaching results.

\section{Conflicts of Interest}

The author declares no conflicts of interest regarding the publication of this paper.

\section{References}

[1] Zhang F. and Li H. (2019). Thoughts on the Safety Management of College Laboratories. Guangdong Chemical Industry, (10): 180-183.

[2] Liu C., Zhang G.W. and Zhu X.L. (2019). Putting Experimental Safety Education throughout Experimental Teaching. Education Teaching Forum, (24): 259-260.

[3] Yin M.Y. (2018). Research on the Management of Basic Chemistry Laboratories in Colleges and Universities. Chemical Engineering Management, (34): 103.

[4] Ji X.Y., Zhou M.Y., Ding L.F. and Yang S.L. (2018). Research on the Education of Experimental Safety and Experimental Norms in Colleges and Universities. Chemical Management, (34): 17-19.

[5] Liu J.P. and Dong C.Z. (2005). University Chemistry. Anhui University Press, Anhui.

[6] Jing Y.J. and Wu Y. (2019). Investigation and Practice of the Status Quo of College Students' Laboratory Safety Awareness. Experimental Technology and Management, (5): 251-254+267.

[7] Wang K.Y. (2018). Chemical Scientific Research Management Countermeasures. Chemical Management, (36): $62-63$.

[8] Zhou T.T. Analysis of the Safety Status of Chemical Laboratories and Self-protection. Chemical Management, (34): 126-127. 